\title{
THE ARC OF WALLY BROECKER'S CAREER
}

\author{
Michael Bender* \\ Department of Geosciences, Princeton University, Princeton, NJ 08544, USA
}

\begin{abstract}
Wally Broecker came to Lamont Geological Observatory as a summer student after his junior year of college. He completed his undergraduate education at Columbia, and by the time he received the bachelor's degree, he was essentially in charge of the Lamont Radiocarbon Laboratory. His $\mathrm{PhD}$ thesis applied radiocarbon dating to two great topics: ocean circulation and glacial-interglacial climate change. In a career that lasted over 60 years, Wally combined his core interests in these two topics with an amazingly diverse range of related studies.
\end{abstract}

Figure 1 is a timeline summarizing the history of Wally's research in paleoclimate and oceanography. Boxes above the timeline correspond to paleoclimate studies, and boxes below to chemical and physical oceanography. Each box represents one research focus that involved an average of perhaps 15 papers.

The early period of Wally's career lasted until 1972, when the Geochemical Ocean Section Study kicked off. During this time, his focus was primarily experimental. In the paleoclimate realm, he helped characterize the nature of glacial cycles by studying the foraminiferal oxygen isotope record in deep sea sediments. This work led to his insight that glacial cycles had a sawtooth shape, with long coolings leading to rapid and dramatic warmings. He also improved the ${ }^{230} \mathrm{Th}$ method of dating corals. With this effort he was able to confirm Milankovitch's hypothesis that glacial cycles were paced by changes in summertime solar heating of the high northern latitudes, where the ice sheets first began to grow.

In the 1960s Wally recognized that a dense global study of the distribution of various oceanic tracers could dramatically advance our understanding of ocean circulation. With Harmon Craig, Derek Spencer, and Arnold Bainbridge, Wally initiated such a program. His own contribution to GEOSECS involved applying the distribution of ${ }^{222} \mathrm{Rn}$ to study air-sea gas exchange and mixing near the sea floor. The greater contribution came from the team's effort to make detailed, high-quality measurements of carbon and radiocarbon distributions, nutrients, and trace metals among other properties. This work eventually led to ongoing international programs, lying at the heart of much oceanographic research, that systematically study the distribution of natural and anthropogenic chemicals in the oceans.

By the mid-1970s, when the Atlantic and Pacific GEOSECS field efforts were completed, Wally refocused his research on the interpretation of existing data rather his own measurements. This change was prompted by the increasing availability of large data sets, collaborators who made measurements, and perhaps Wally's belief that he could inspire people to do studies that advanced his research agenda while elevating the broader science. The latter view was wellfounded: for example, Wally initiated the effort leading to the drilling of the GISP2 and GRIP ice cores.

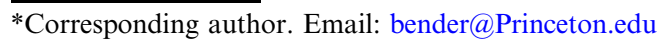




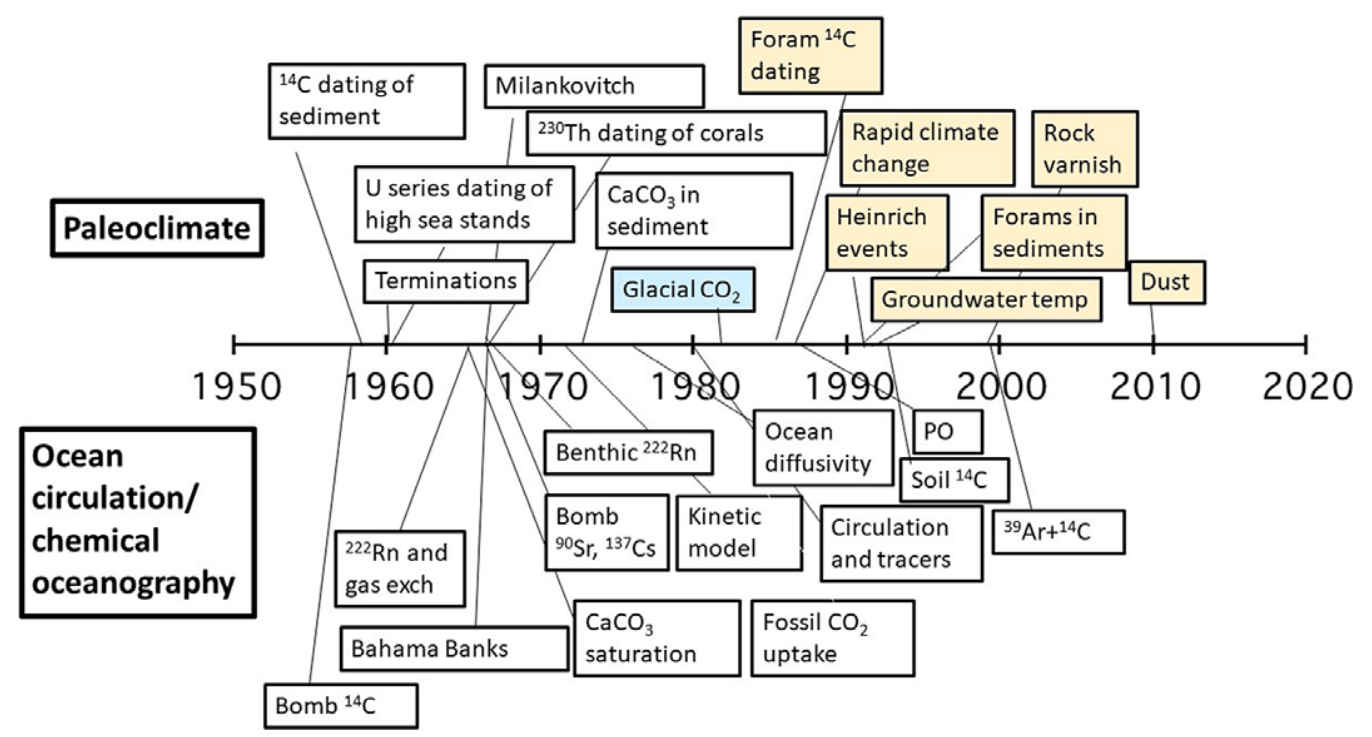

Figure 1 Timeline of Broecker's contributions.

Thus after GEOSECS, Wally wrote a long series of papers aimed at understanding the impact of ocean mixing on the distribution of biologically active chemicals in the ocean. In the 1980s, perhaps stimulated in part by the opportunities associated with accelerator mass spectrometry, Wally shifted his focus to earth's climate history during the past $\sim 25 \mathrm{kyr}$ or so. Wally made three seminal contributions. First, he recognized that Heinrich events were exceptional phenomena recording fundamental processes of the glacial and deglacial climate systems. Second, he called attention to the role of the Atlantic Meridional Overturning Circulation as a fundamental cause of rapid climate change. Third, starting in 1982, he outlined the proper approach to understanding atmospheric $\mathrm{CO}_{2}$ concentration changes between glacial and interglacial times. His original hypotheses were incomplete and were modified or amended. However, Wally wrote the rules for models of glacial-interglacial $\mathrm{CO}_{2}$ change, including invoking the oceanic carbon inventory, ocean temperature, salinity, and nutrient distributions, and the relationship between ocean carbon and nutrient fluxes. And, of course, Wally's work on calcium carbonate dissolution in deep-sea sediments provided a guide for assessing the role of carbonate in glacial-interglacial $\mathrm{CO}_{2}$ change.

Wally carried out a wide range of ancillary projects involving new insights and methods (Figure 2). One involved an early effort, with Jean Jouzel and Randy Koster, to embed water isotopes in global circulation models. Another involved assessing the new information about ocean circulation derived by complementing oceanic radiocarbon measurements with ${ }^{39} \mathrm{Ar}$ (269-yr half-life).

Finally, Wally was intrigued by the possibility of manipulating natural systems to understand geochemical processes on a larger scale than was possible in most lab studies. He carried out three major efforts with this approach (Figure 3). One, with David Schindler, involved adding tracers to Canadian Lakes to study various chemical and limnological processes. The second was amending mesocosms at the University of Rhode Island with radiolabeled trace metals, to 


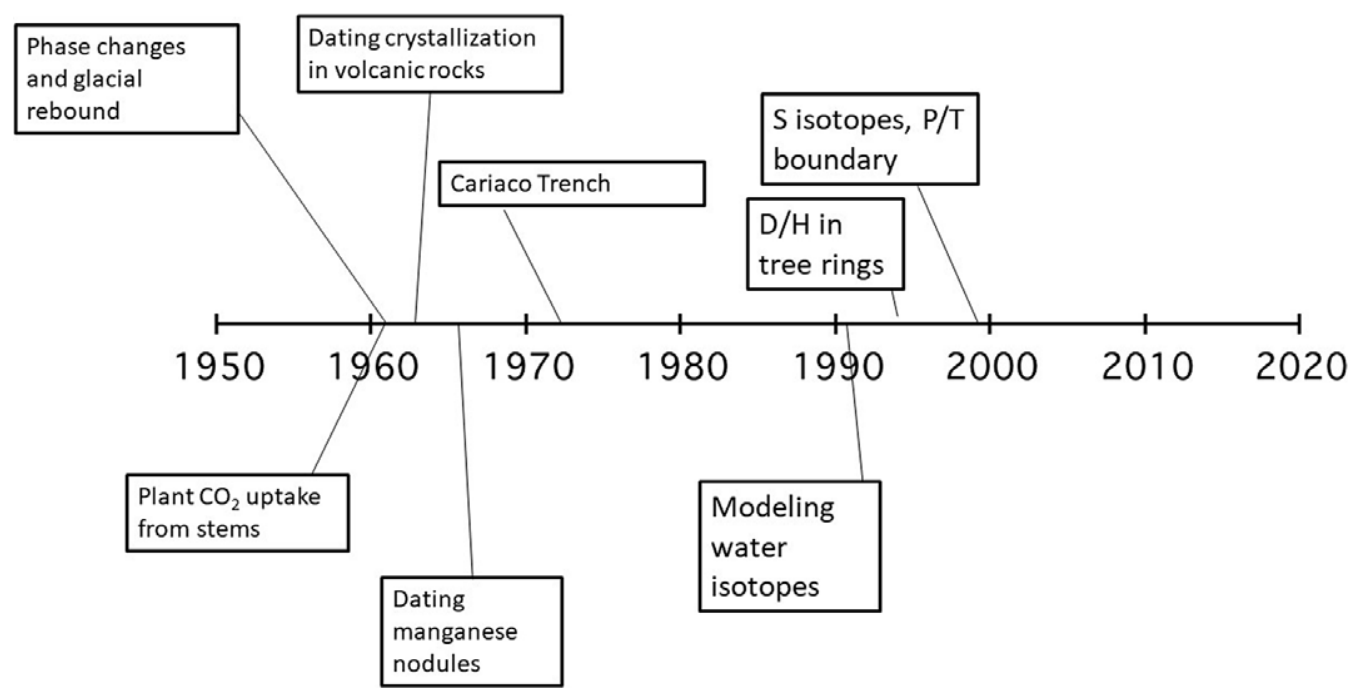

Figure 2 Broecker's one-offs.

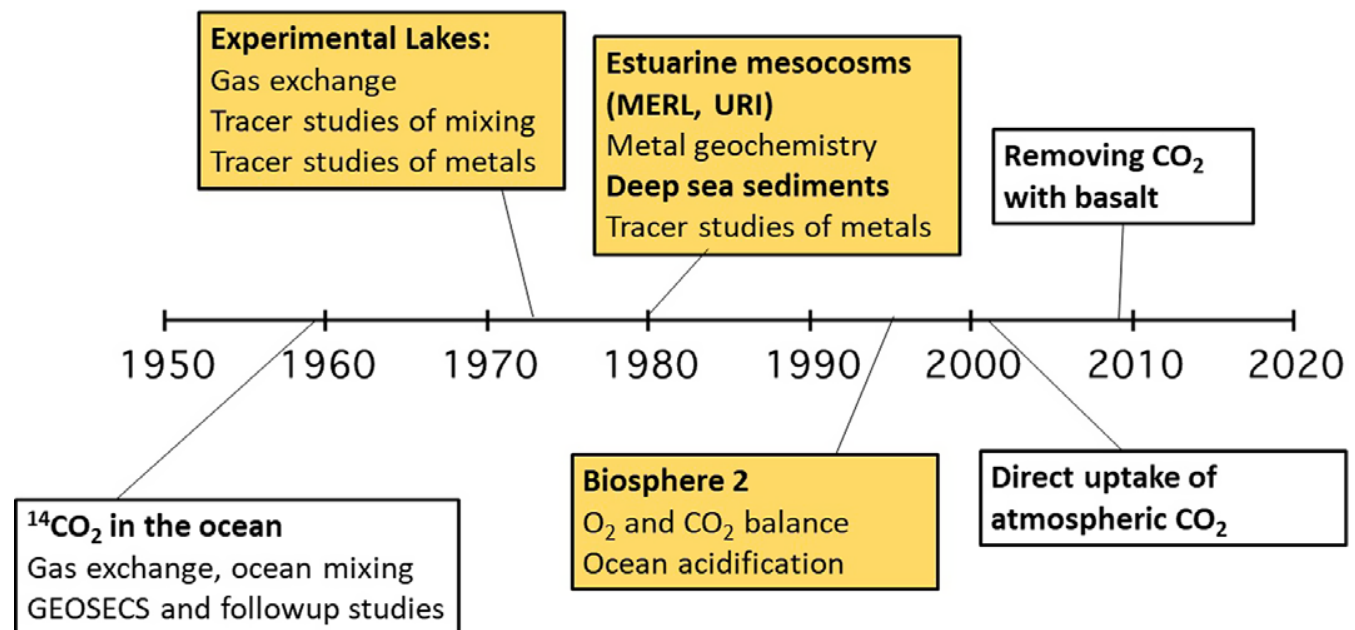

Figure 3 Wally does manipulative experiments.

study their behavior in estuaries and nearshore waters. The third was assessing the mass balance of $\mathrm{C}$ and $\mathrm{O}_{2}$ in Biosphere 2, and using this large, enclosed facility to do a range of manipulative experiments.

I personally sometimes think about Wally as a mutant. Compared with most of us, he was more brilliant, a deeper and quicker thinker, endlessly curious, more energetic, more enthusiastic, and more compelling. Wally was perfectly aligned with his time. The beginning of his career roughly coincided with the dawn of systematic research in oceanography, paleoclimate, and the broader field of geochemistry. Wally worked on these topics from the start, and made them his own. No one today could have a career working on 
environmental geosciences topics as broad as Wally worked on, because the field has grown, there is dispersed excellence, and there is too much information to be grasped by one person. Wally leaves a legacy of accomplishment, leadership, and joy of doing science that will continue to have a profound influence on many of us off into the future. 